\title{
INDUÇÃO DE RAÍZES EM ESTACAS SEMILENHOSAS DE AZALÉIA ATRAVÉS DA APLICAÇÃO DE ÁCIDO NAFTALENO-ACÉTICO EM SOLUÇÃO'1
}

\section{ROOT INDUCTION IN RHODODENDRON SEMIHARDWOOD CUTTINGS TREATED WITH SOLUTION OF NAPHTHALENE ACETIC ACID}

\author{
Denise Bruginski de CARVALHO² \\ Lenir Maristela SILVA ${ }^{3}$ \\ Katia Christina ZUFFELLATO-RIBAS ${ }^{4}$
}

\begin{abstract}
RESUMO
A azaléia (Rhododendron x simsii Planch.), planta ornamental da família Ericaceae, formada por hibridação e melhoramento na China, é usualmente propagada por estaquia. Estacas semilenhosas com aproximadamente dez centímetros de comprimento foram retiradas da base de brotações jovens de azaléia coletadas no mês de setembro de 2000, nas dependências do setor de Ciências Biológicas da Universidade Federal do Paraná. O experimento foi conduzido em delineamento de blocos completamente casualizados, com três tratamentos e quatro repetições. Os tratamentos consistiram de diferentes concentrações de NAA (ácido naftaleno-acético) em solução, sendo 0, 2500 e $5000 \mathrm{mg} \cdot \mathrm{L}^{-1}$, nas quais foram imersas as bases das estacas por um período de 15 segundos. As estacas foram mantidas sob câmara de nebulização, em tubetes contendo vermiculita, por um período de 63 dias. Foram avaliados: a) estacas com brotações; b) estacas enraizadas; c) estacas vivas; d) padrão de enraizamento; e) comprimento médio das três maiores raízes. A aplicação de NAA não alterou a porcentagem de sobrevivência, brotação e enraizamento de estacas semilenhosas de azaléia. Além do balanço hormonal outros fatores são importantes na formação de raízes, pois mesmo sem aplicação de fitorregulador é possível induzir o enraizamento de azaléia.
\end{abstract}

Palavras-chave: Azaléia, NAA, estaquia, Rhododendron $x$ simsii Planch.

\begin{abstract}
The rhododendron (Rhododendron $x$ simsii Planch., Ericaceae) has been obtained by genetic improvement in China and it is usually propagated by cuttings. Semihardwood cuttings with approximately 10 $\mathrm{cm}$ of lenght were obtained from basal portion of new sprouts collected in September, 2000 from rhododendron cultivated in Setor de Ciências Biológicas of Universidade Federal do Paraná. The experiment was installed in random ized blocks with three treatments and four replications. The treatments were consisted of different NAA concentrations in watessolution $\left(0 ; 2.500\right.$ and $\left.5.000 \mathrm{mg}^{-\mathrm{L}^{-1}}\right)$ applied by imersion to the cuttings base for 15 seconds. The cuttings were kept in greenhouse under mist irrigation system in small tubes with vermiculite for 63 days. Parameters evaluated were: a) Cuttings spicuting; b) Cuttings rpcuting; c) Cuttings survival; d) Rooting pattern; e) Average length of the three longest roots. NAA application did not altered the survival percentage, sprout and rooting of rhododendron semihardwood cuttings. Beside hormonal balance, other factors are important in the root formation, because the roots of rhododendron cuttings were obtained without being treated a treatment with plant growth regulators.
\end{abstract}

Key-words: rhododendron, NAA, cutting, Rhododendron $x$ simsii Planch.

\footnotetext{
${ }^{1}$ Trabalho apresentado na disciplina de Fisiologia da Reprodução Vegetal, do Curso de Pós-graduação em Agronomia - Produção Vegetal, Universidade Federal do Paraná

${ }^{2}$ Engenheira Agrônoma, CREA 28300 D, MSc., doutoranda do Curso de Pós-graduação em Agronomia - Produção Vegetal Universidade Federal do Paraná. Bolsista CAPES. denisehb@agrarias.ufpr.br.

${ }^{3}$ Bióloga, MSc., professora Assistente do CEFET/PR - Unidade de Pato Branco, doutoranda do curso de Pós-graduação em Agronomia - Produção Vegetal, Universidade Federal do Paraná. lebotanica@onda.com.br.

${ }^{4}$ Bióloga, Dra., CRB 14254-01, professora Adjunta do Departamento de Botânica, Universidade Federal do Paraná. kazu@bio.ufpr.br.
} 
CARVALHO, D.B. et al. Indução de raízes em estacas semilenhosas...

\section{INTRODUÇÃO}

A azaléia (Rhododendron $x$ simsii Planch.) é uma planta ornamental da família Ericaceae muito cultivada no Brasil. Tem sua origem na China, sendo formada por hibridação e melhoramento. Possui foIhas decíduas ou semi-decíduas no inverno. As flores são variadamente coloridas, brancas, vermelhas, arroxeadas, róseas, simples ou dobradas, não raro listradas, surgindo no outono ou inverno (10).

As azaléias são intensamente cultivadas em vasos, bordaduras, em maciços ou grupos mantidos podados ou não. As azaléias apreciam os solos ácidos, porém férteis (10).

A propagação da azaléia para fins comerciais é realizada através de estacas, obtendo-se melhores resultados com estacas semilenhosas (2). Entretanto, o enraizamento das estacas é, muitas vezes, difícil, com pequena porcentagem de produção (2).

As azaléias decíduas podem ser propagadas facilmente por mergulhia ou alporquia, porém o processo de enraizamento é mais demorado do que o da maioria dos arbustos com flores. As estacas caulinares desta espécie não se enraízam facilmente. As estacas podem ser retiradas em qualquer época, depois de iniciado o crescimento, mas normalmente enraízam melhor, se retiradas em fins do verão, depois que a madeira está mais lignificada. É importante manter as estacas fixadas sob ambiente bem úmido com nebulização de uma ou duas vezes por dia, evitando o excesso de umidade (8).

Para acelerar e promover o enraizamento de estacas, Hartmann et al. (6), sugerem o emprego habitual de reguladores de crescimento, mais especificamente do grupo das auxinas, os quais induzem à uma maior porcentagem de formação de raízes e uniformidade de enraizamento. Especificamente para o gênero Rhododendron os mesmos autores recomendam utilizar altas concentrações de IBA em talco ou solução de 10.000 a $20.000 \mathrm{mg} \cdot \mathrm{L}^{-1}$.

Em várias espécies vegetais, o enraizamento é grandemente aumentado pela adição de auxinas sintéticas, sendo o fitorregulador de maior sucesso, o IBA (ácido indol-butírico) (12). O NAA é um composto um pouco mais tóxico que o IBA, devendo ser usado em concentrações menores para não trazer danos à planta. O fitorregulador IBA é mais eficaz, porém, mais caro que o NAA, o que dificulta sua utilização comercial (1)

Para fins de estudo formulou-se a seguinte hipótese: se a coleta de estacas feita no período de florescimento diminui o percentual de enraizamento então a aplicação de NAA na base das estacas proporcionará aumento no percentual de enraizamento porque irá suprir a carência de auxinas endógenas. Com o objetivo de avaliar o enraizamento de estacas de azaléias coletadas no final do inverno e tratadas com NAA, conduziu-se o presente trabalho.

\section{MATERIAL E MÉTODOS}

Estacas semilenhosas com aproximadamente dez centímetros de comprimento foram retiradas da base de brotações do ano de azaléia (Rhododendron $x$ simsii Planch.) coletadas no mês de setembro de 2000, nas dependências do Setor de Ciências Biológicas, da Universidade Federal do Paraná.

O experimento foi conduzido em delineamento de blocos inteiramente casualizados com três tratamentos, quatro repetições e com dez estacas por repetição. Diferentes concentrações de NAA em solução aquosa foram utilizadas, sendo 0, 2500 e 5000 $\mathrm{mg} \cdot \mathrm{L}^{-1}$.

As estacas foram confeccionadas cortando-se a base em bisel e mantendo-se duas folhas com a área reduzida à metade na porção apical. Em seguida, receberam tratamento fitossanitário com hipoclorito de sódio a $0,5 \%$, durante cinco minutos e lavagem posterior em água corrente.

Para os tratamentos, as bases das estacas permaneceram imersas nas soluções contendo fitorregulador por um período de 15 segundos. As estacas foram mantidas sob câmara de nebulização, em tubetes contendo vermiculita como substrato, por um período de 63 dias.

Foram avaliados:

a) estacas com brotações: verificação visual do surgimento de brotos, valor percentual;

b) estacas enraizadas: verificação visual do surgimento de raízes, valor percentual;

c) estacas vivas: verificação visual do número de estacas vivas, valor percentual;

d) comprimento médio das três maiores raízes: medido com auxílio de régua em todas as estacas, obtendo-se a média, em centímetros.

e) padrão de enraizamento: adoção de uma escala de zero a três para diferenciar o volume radicial desenvolvido no período (Figura 1).

Os resultados foram submetidos à análise de variância utilizando o programa MSTATC. As variâncias dos tratamentos foram analisadas pelo teste de Bartlett para verificação da homogeneidade, e havendo necessidade, os dados foram transformados utilizando a fórmula Ö $x+1$. As variáveis cujas variâncias mostraram-se homogêneas tiveram as médias dos tratamentos testadas por meio de teste $F$, em nível de $5 \%$ de probabilidade. 
CARVALHO, D.B. et al. Indução de raízes em estacas semilenhosas...

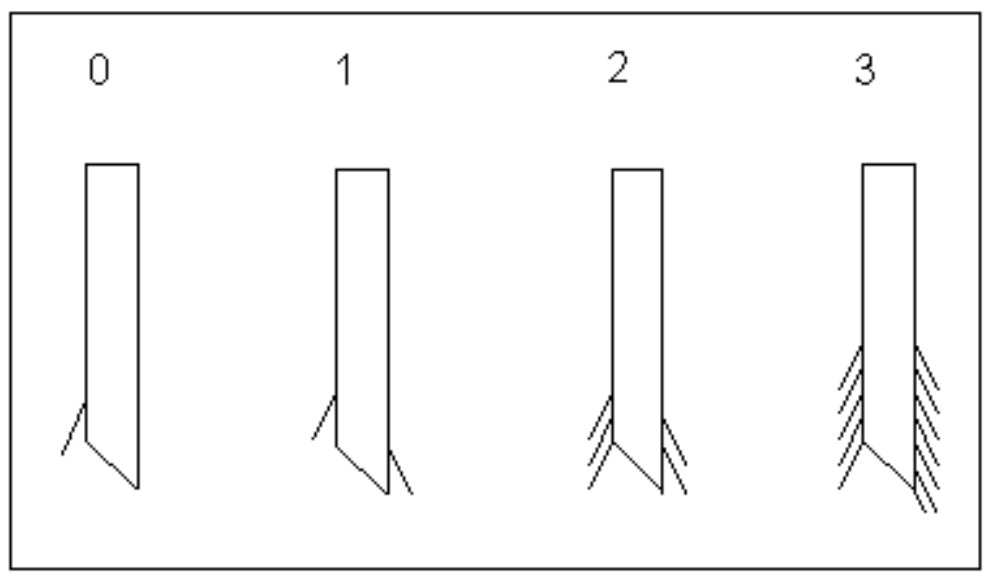

FIGURA 1 - Padrões de enraizamento de estacas de azaléia: 0 - estacas com apenas uma raiz; 1 - estacas com duas raízes; 2 - estacas com poucas raízes; 3 - estacas com muitas raízes.

\section{RESULTADOS E DISCUSSÃO}

O uso de NAA em solução promoveu uma melhor formação de raízes em estacas semilenhosas de azaléia, valores estes, contudo, não significativos, de acordo com o teste $\mathrm{F}$ a $5 \%$ (Tabela 1).

$\mathrm{Na}$ avaliação, $99,2 \%$ das estacas permaneceram vivas e emitiram brotações. A constatação de $18,3 \%$ de estacas vivas e não enraizadas pode ser um indicativo de que não houve tempo suficiente para que todas emitissem raízes.

Harrington (5), em seu trabalho com diversas cultivares de azaléia, afirma que o NAA aumenta a taxa de sobrevivência de estacas em $11,7 \%$, enquanto IAA (ácido indol acético) e IBA reduzem a sobrevivência. $O$ autor realizou a avaliação cerca de 90 dias após a instalação, e no caso do presente experimento, apesar da elevada taxa de sobrevivência das estacas de azaléia, a avaliação feita aos 63 dias não pode ser conclusiva com relação a influência da aplicação do NAA sobre o parâmetro sobrevivência, mas podese considerar que a manutenção das estacas vivas pode levar a um maior percentual de enraizamento.

TABELA 1 - Médias obtidas para porcentagem de estacas com brotação, não enraizadas, enraizadas, comprimento médio das três maiores raízes e padrões de enraizamento de azaléia em função de diferentes doses de NAA, aplicados na forma de solução, na base das estacas. Curitiba, PR, 2000.

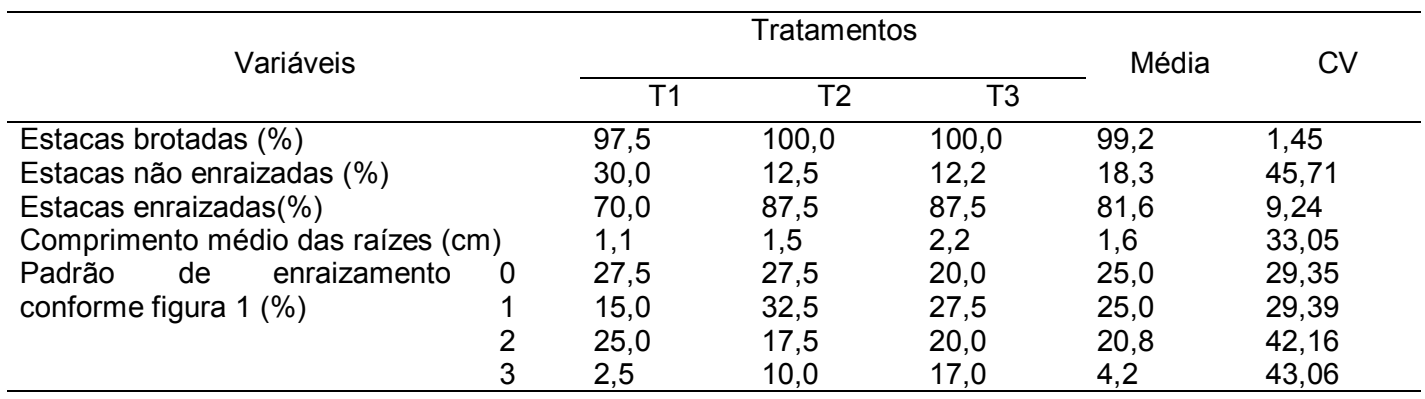

${ }^{1} \mathrm{~T} 1$ = NAA $0 \mathrm{mg} \cdot \mathrm{L}^{-1} ; \mathrm{T} 2$ = NAA $2500 \mathrm{mg} \cdot \mathrm{L}^{-1} ; \mathrm{T} 3=\mathrm{NAA} 5000 \mathrm{mg} \cdot \mathrm{L}^{-1}$.

${ }^{2} \mathrm{CV}=$ Coeficiente de Variação. 
CARVALHO, D.B. et al. Indução de raízes em estacas semilenhosas...

As médias observadas para porcentagem de estacas enraizadas, sem diferença estatística, sugerem que a aplicação de NAA não é necessária para o enraizamento de estacas de Rhododendron $x$ simsii Planch., sendo a média de enraizamento de todo o experimento de $81,6 \%$. Isto confirma a afirmação de Lorenzi e Souza (11), de que esta espécie multiplicase por estacas de ponteiros, plantadas em estufas e explica nossos resultados.

É importante resgatar que no gênero Rhododendron pode haver variações quanto a indução de enraizamento pois no experimento de Hwang et al. (9) foi encontrada a melhor taxa de enraizamento de estacas de Rhododendron mucronulatum com 2000 mg. $\mathrm{L}^{-1}$ de NAA também aplicado durante 15 segundos.

Já no que se refere a espécie do presente trabalho os resultados se assemelham aos de outros pesquisadores, apesar de utilizarem outros fitorreguladores. Chalfun et al. (2) conduziram experimento com estacas coletadas no mês de abril, utilizando IBA em concentrações de 0,100 e 200 mg.L-1, durante 24 horas, com avaliação aos 120 dias e não houve diferença significativa de enraizamento comparando as testemunhas com as estacas submetidas ao tratamento com IBA. Górecka (3), verificou o efeito do IBA sobre o enraizamento de azaléia em concentrações de 1000,2500 e 5000 mg.L $\mathrm{L}^{-1}$ durante 5 segundos de imersão. A avaliação com 55 dias demonstrou $100 \%$ de enraizamento para todos os tratamentos e a testemunha apresentou $60 \%$ de enraizamento.

Hwang et al. (9) verificaram que a taxa de enraizamento de estacas de Rhododendron mucronulatum tratadas com NAA decrescia a medida que as plantas entravam em período reprodutivo. Tratando-se da espécie em estudo, a coleta em setembro, quando as plantas estavam em plena floração, não impediu a indução da formação do sistema radicial, pois mesmo a testemunha apresentou elevado percentual de enraizamento.

$\mathrm{O}$ fato das testemunhas terem enraizado, provavelmente se justifica devido a presença de folhas mantidas nas estacas. Hartmann et al. (6), mencionam que a presença de folhas nas estacas influencia o enraizamento e que as auxinas são muito importantes neste processo, pois a auxina produzida nas folhas novas e nas gemas, move-se naturalmente para a parte inferior da planta, acumulando-se na base do corte, junto com açúcares e outras substâncias nutritivas. A formação de raízes é, aparentemente, dependente de um nível ótimo de auxina, pois estas incentivam a divisão celular além de promover a síntese de RNA, cujo, intervém na iniciação do primórdio radicial $(4 ; 7)$.

Apesar de não haver diferença significativa entre os tratamentos, pode-se verificar que houve uma tendência ao aumento do comprimento das raízes nos tratamentos com NAA.

Não foi possível estabelecer relação entre os padrões de enraizamento e os tratamentos. Parece não haver nenhum efeito da aplicação de NAA na dosagem utilizada sobre a quantidade de raízes emitidas pelas estacas para esta espécie.

\section{CONCLUSÕES}

- A aplicação de NAA não aumentou significativamente a porcentagem de sobrevivência, brotação e enraizamento de estacas semilenhosas de Rhododendron $x$ simsii Planch. coletadas no final do inverno.

- Além do balanço hormonal outros fatores são importantes na formação de raízes, pois mesmo sem aplicação de fitorregulador obteve-se enraizamento de Rhododendron x simii Planch.

\section{REFERÊNCIAS BIBLIOGRÁFICAS}

1 ALVARENGA, L. R.; CARVALHO, V. D. Uso de substâncias promotoras de enraziamento de estacas frutiferas. Informe Agropecuário, v.9, n.101, p.47-55, 1983.

2 CHALFUN, N. N. J.; HOFFMANN, A; CHALFUN JR, A; JESUS, A. M. dos S. Efeito da auxina e do anelamento no enraizamento de estacas semi-lenhosas de azaléia. Lavras: Ciência e Agrotecnologia, v.21. n.4, p.516-520, out/dez., 1997.

3 GÓRECKA, K. The effect of growth regulators on rooting of ericaceae plants. Acta Horticultural. Research Institute of Vegetative Crops. n.91, p.483-489. 1979.

4 HAISSIG, B. E. Meristematic activity during adventitious root primordium development - inlfuences of endogenous auxin and aplplied gibberelic acid. Plant Physiology. v.49, p.886-892, 1972.

5 HARRINGTON, J.L. Rhododendron propagation. American Rhododendron Society Journal. v.44:3, p.173-176, 1990.

6 HARTMANN, H. T. et al. Plant Propagation: principles and pratctices. 6 ed. New York: Englewood Clipps/Prentice Hall, 1997. 770p.

7 HESS, C. E. Internal and external factos regulating root initiation: root growth. 2.ed. London: Buttersworth, 1969.

8 HILL, L. Segredos da Propagação de Plantas. São Paulo: Nobel, 1996.340p.

9 HWANG, S. et al., Effect of cutting dates and rooting promoters on rooting of Rhododendron mucronulatum Turcz. Korean Journal of Horticultural Science and Technology. v. 16:1, p. 33-36, 1998.

10 LORENZI, H. e SOUZA, H. M. de Plantas ornamentais no Brasil: arbustivas, herbáceas e trepadeiras. Nova Odessa/SP: Plantarum, 1995.720p. 
CARVALHO, D.B. et al. Indução de raízes em estacas semilenhosas...

11 LORENZI, H. e SOUZA, H.M de. Plantas ornamentais no Brasil: arbustivas, herbáceas e trepadeiras. 2 ed. Nova Odessa: Instituto Plantarum, 1999.1088p.

12 NORDSTRÖM, A C.; JACOB, F. A; ELIASSON, L. Effect of exogenous indole-3-acetic acid and indole-3-butiric acid on internal levels of the respective auxins and their conjugation with aspartic acid adventitious root formation in pea cuttings. Plant Physiology. v.96, p. 856-61, 1991.

Recebido em 02/05/2001 Aceito em 08/03/2002 